\title{
Social networks in cultural industries
}

\author{
Reyes Gonzalez, University of Alicante \\ Juan Llopis, University of Alicante \\ Jose Gasco, University of Alicante
}

September 2014

Authors would like to express their gratitude to CMUA academic staff (http://cusocommunitymanager.com), in particular Oscar Carrión

(Oscar.carrion@ua.es), for their support with the empirical part of this study. Authors thank Maria Teresa del Val (University of Alcalá) for her comments on previous versions of the paper. Authors alone are responsible for all the limitations and mistakes of the study. Please send correspondence to: Reyes Gonzalez, Business Organization Department, University of Alicante, Campus Sant Vicent del Raspeig, s/n. Postcode 03080. Tel. and Fax: (+34) 5903606 Alicante, Spain. mr.gonzalez@ua.es; Juan Llopis, University of Alicante, juan.llopis@ua.es; Jose Gasco, University of Alicante, jl.gasco@ua.es. 


\begin{abstract}
Although cultural industries can benefit from social networks in many ways, few Spanish studies examine the extent to which firms within this economic sector actually use such networks. This study's bjective is to investigate the role of online social networks in Spanish cultural firms. The study begins with a literature review on cultural industries and social networks. Then the study proceeds to a Delphi analysis that draws upon experts’ opinions. Results reveal a predominance of utilitarian uses over expressive ones, as well as an overriding use of proactive motivations rather than reactive ones within the context of cultural firms' use of social networks. The study confirms the profitability of these networks and the transfer of influence or power from providers to the consumers of cultural goods and services.
\end{abstract}

Keywords: Online social networks; Cultural industries; Delphi method; Spain 


\section{Introduction}

Cultural industries in Spain account for 4\% of GDP and about 750,000 jobs.

Given that these industries intensively use qualified employees, this economic sector is clearly important to Spain.

The nature of their target audience and the type of product cultural industries offer explain why social networks use in cultural industries yields manifold advantages (Haegeman, Cagnin, Könnölä, \& Collins, 2012). Nevertheless, few Spanish studies investigate the extent to which cultural industries actually use social networks. This study examines the role of online social networks in Spanish cultural firms. Specifically, this research seeks to verify the most prevalent uses of online social networks, as well as the main motivations for such use, customers' role, and the impact that such networks have on business profitability. Collecting the opinions of a panel of qualified social networks experts helps achieve these goals. The paper has the following structure: Section 2 reviews literature on cultural industries and social networks. Section 3 presents methodology. Section 4 summarizes the results. Section 5 concludes the study.

\section{Literature review}

\subsection{Culture and Information and Communications Technologies}

The innovative nature of cultural initiatives makes them hard to define. Cultural industries are an aggregate of economic sectors with a link to the production and distribution of symbolic works, stemming from creative processes, and targeting consumer markets. These industries comprise reading and writing (press, publishers, books, etc.), image and sound (TV, radio, cinema, copyright recorded music, etc.), 
performing arts (shows, theatre, concerts, etc.), and other cultural products; in other words, historical heritage, restoration activities, art market, and exhibitions.

Culture and creativity have a direct link with Information and Communication Technologies (ICTs). This link exists because ICTs constitute a basic tool for communication and the transmission of knowledge, as well as for exchanging experiences and emotions necessary for creativity. Cultural assets are intangible because culture demand does not require the exchange of any particular goods. Instead, this demand requires a set of values and services. This need is especially significant regarding historical heritage goods. A visit to a museum, cathedral or historical building only requires a set of associated values and services ranging from aesthetic emotion to cognitive and educational value. Crucially, cultural assets are not simply a product. Instead, they involve a qualitative cultural experience. Information signals (e.g. experts' opinions) influence emotions when listening to a song or admiring a picture. ITCs can disseminate —or even create— intangible cultural assets. Finally, many businesses in cultural industries rely on the emotions they generate among users and on the need for a positive environment for cultural creativity. Social networks allow consumers to share emotions and interests that generate desirable membership and differentiation feelings among customers. Greenacre, Freeman, \& Donald (2013) identify social networks with tribes. Emotions incorporation into business strategies becomes paramount for cultural firms. Cultural and creative firms need to move people through their products so that people become part of cultural firms' influence network. Online social networks are appropriate for channeling creativity, intangibility, and emotions that characterize this sector (Sánchez-Franco, Buitrago-Esquinas, \& Yñiguez, 2012).

\subsection{Online Social Networks}


Social networks are communities of people who share some interests. The Internet, along with Web 2.0 and 3.0 technologies, amplifies real-life social networks. According to Gneiser, Heidemann, Klier, Landherr, \& Probst (2012), online social networks allow individuals and firms to build public or semi-public profiles within the system, to create a list of connections with users and to match their list of connections with those of others within the system. Both private and public sectors are discovering the amount of applications of these technologies (Haegeman et al., 2012). However, using such a contact network may have adverse effects. The influence shift from providers to customers because of networks' extensions as well as the possible link between this technology and business profitability are also factors to take into consideration. This study addresses these issues: a) social networks uses; b) network users' motivations; c) customers' influence through these networks; and d) networks' impact on profitability.

a) Social networks’ uses. Business organizations are increasingly developing their own networks to distinguish themselves from competitors and to provide potential consumers with greater added value.

Community membership may act as a measure of adhesion to a certain lifestyle, which permits members to be different from other consumers. This case exemplifies external use of networks. This use allows the firm to connect customers and to give them a space for sharing experiences. Finally, customers can deepen the relationship with firms, moving from fans to true champions and stakeholders (Sashi, 2012; Zaglia, 2013).

Networks internal use is also important to establish communities such as those comprising providers or employees (Sinclaire \& Vogus, 2011). Personal contacts within social networks may create strong working relationships (Koch, Gonzalez, \& Leidner, 
2012). They also contribute to create Knowledge Management Systems through knowledge and experiences exchange (Magnier-Watanabe, Yoshida, \& Watanabe, 2010). In this sense, social networks can help create two kinds of ties among members of a work team: instrumental and expressive (Zhong, Huang, Davidson, Yang, \& Chen 2012). Instrumental ties often emerge from formal relationships at the workplace. They can effectively transfer physical, financial or informational resources within organizations. Instrumental ties allow team members obtain information, advice, and experience from other team members. Such ties are utilitarian, since their purpose is professional. Conversely, expressive ties involve exchanging feelings and satisfying affection needs, social support and group membership feelings.

b) Network users' motivations. According to Xu et al. (2012), the motivations for using social networks divide into two types: utilitarian and hedonic. Social networks create a sense of connection between users and smartphones allow users to have always connection. Networks make effective, efficient use of communication channels to organize social activities (Bendle \& Patterson, 2010) and disseminate news and messages without having to send the same content to several individuals due to immediate access and coordination, which behave like two utilitarian rewards. On the other hand, hedonic motivation (Sledgianowski \& Kulviwat, 2009) resides in consumers’ emotional needs and captures non-functional benefits like fantasy, happiness, sensuality, enjoyment, or delight.

Casaló, Flavián, \& Guinalíu (2010) summarize the motivations for using social networks into four types of needs that networks satisfy. These needs comprise: dealing with interesting issues, establishing relationships, living fantasies, and carrying out transactions. Chai \& Kim (2012) analyze motivations for using network according to social and technological issues. Social issues users' feeling of network membership, 
social interactions that may create trust, ethical culture inherent to network users, or even using networks as gossip vehicles (Okazaki, Rubio, \& Campo, 2013). Technological issues refer to the possibility of protecting users’ security; for example by providing the option of sharing information publicly, only with friends or keeping the information personal. Sinclaire \& Vogus (2011) pose another dichotomy by classifying motivations for networks use into proactive and reactive. Proactive involve firms setting specific objectives and well-defined strategies for network use. Reactive refers to fashion effect that involves following a trend and using networks more passively. However the absence of clear goals creates an additional degree of uncertainty around how to embrace technology.

c) Customers’ influence through social networks. By using social networks, customers' empowerment grows. The Internet is nowadays a highly interactive medium since the arrival of Web 2.0 and 3.0 technologies. Users can create content and obtain information. A user’s feedback on firms’ products is essential for implementing suitable marketing measures for those products (Bodendorf \& Kaiser, 2009; Garrigós-Simón, Lapiedra-Alcamí \& Barberá-Ribera, 2012). Customers can comment on products and influence one another in their opinions through social networks. In some sense, users become digital evangelists and prosumers (San José-Cabezudo, Camarero-Izquierdo \& Rodríguez-Pinto, 2013). They are digital evangelists because their opinions and experiences can either help spread products/services or contribute to their decline. They are prosumers because their views can influence new products or services contributing in some ways to firms' creative processes. In this framework, users can ultimately become trendsetters. Consequently, social networks clearly change the power balance between consumers and good/services producers due to customers’ power being definitely greater than before. 
d) Networks’ impact on profitability. Undisputedly, social networks directly affect profitability, as they lead to cost reductions and revenue increases (Bughin \& Chui, 2010). This positive impact results from the multiple advantages that consumer participation can bring to organizations. For example, consumers represent a source of first-hand information for firms, thus reducing the costs of coordination and information transmission and transforming word of mouth campaigns within social networks into large marketing campaigns. Customers’ participation in social networks also lowers technical service costs, as individuals may assist each other to solve problems arising from products’ or services’ use. Finally, social network interactions allow firms to evaluate customer value for community-based online service companies (Joo, Kim, \& Yang, 2011). As for revenues, income increase due to advertising through social networks is worthy of mention.

\section{Methodology}

A two-stage Delphi study analyzes the role of social networks in cultural firms. In the first round, academic teachers throughout Spain giving courses and master's degrees on physical, semi-physical and online training in social network management complete a questionnaire about social networks inside cultural industries. This exercise yields a total of 19 usable questionnaires. Questionnaires contain 13 items. The first six refer to responding experts’ profile (age, gender, educational level, social networks use, years of experience with social networks, and connection with cultural industries). Most experts are workers or ex-workers from cultural industries and have around seven years of expertise in social networks use. All of them use five or more social networks. Data about experts’ profiles is available upon request. 
The next four items focus on how social networks contribute to cultural industries, motivations behind their use, changes affecting customers' influence or power and impact of networks on business profitability. Sinclaire \& Vogus (2011) provide the main reference for these items. Finally, the last three questions solicit information on networks' importance on cultural industries. This study classifies items in the last seven questions according to a seven-point Likert scale. The first six questions are open.

The second round relies on Dhaliwal \& Tung's (2000) methodology, using the Delphi coordinator, which edits, clarifies, integrates, and summarizes data after collecting the interviewees’ responses. Unlike other studies, second round entails more than just sending the initial questionnaire. This stage also involves results summary to prepare seven reflections on which the interviewees must give their opinion.

Respondents return 10 questionnaires in the second round, enough according to Okoly \& Pawloski’s (2004) recommendations on the Delphi method.

According to these authors, a Delphi study may have two or more rounds. Despite a fairly small number, two rounds are sufficient (Hayne \& Polland, 2000; Kaynak, Bloom, \& Leibold, 1994). Experts may also lose interest in the study if they have to face too many rounds (Loo, 2002). For this reason, González, Gascó, \& Llopis (2006, 2010) use just two rounds.

\section{Results from the first and second rounds}

Figures 1 to 5 offer a concise representation of the outcomes from the first round of questions. During the second round, experts receive these figures and a questionnaire. This questionnaire is available upon request. The following discussion reports the 
results of the experts' responses. We use quotes coming from the questionnaires to illustrate the results.

\subsection{Uses of social networks}

Figure 1 here.

According to experts, cultural industries can adopt social networks in a wide variety of ways (see Figure 1). Social networks use in such industries predominantly promotes the firm's brands, services, or products and collects information that can improve these assets. Therefore, utilitarian uses aiming at information exchange prevail over expressive ones aiming at emotions. Another result is that customers' or users' education and creation of internal communities (among the firm's workers) are some of the least important uses. Experts support this conclusion, arguing that networks, "represent an ideal channel to obtain information, at all times bearing in mind that critical users are more communicative than satisfied ones.” However, one panelist highlights the importance of expressive network uses as well, pointing out that, “expressive uses are also important because the opinion or recommendation of a product is nourished by a subjective or emotional component... The act of purchasing is not only based on the product's objective features, but also on a subjective or emotional component linked to the personal experience of others, which can be shared through networks.”

4.2. Main motivations for social network use

Figure 2 here.

Cultural industries mainly use social networks to connect with young generations - the main social networks users. Through these actions, cultural industries 
seek to obtain information about the environment, which can help them offer innovative products to the community. The least relevant motivations include cost (low or nonexistent), networks use by others (customers, providers, or competitors), or the protection of the firm's products or services. For this reason, first-round results imply that motivations are proactive rather than reactive. In other words, investing in social networks constitutes a strategy for connecting with community and potential customers, rather than being a defensive reaction to potential threats from business context, either by mimicry, fashion, or costs. Eight out of 10 interviewees in the second round confirm this idea, highlighting that, "their [social networks] low cost is not a motivation, since social network management requires a time dedication that makes it necessary to allocate part of the budget to the areas of training and human resources.” Another expert argues that, "the active and reactive options are valid and compatible", adding that, "the reactive use of the industry also contributes to obtaining feedback from users, thus making it possible to improve the product.”

\subsection{Degree of customers' influence in social networks}

Customers can influence cultural industries through social networks use. The experts give an above average score (5.76 out of a maximum of 7 ) to this issue in the first round, and nine out of 10 experts support this assessment in the second round. Some of them highlight the fact that "customers increasingly decide which cultural project comes to fruition," and that customers "can be influential because they can make a lot of noise, whether it is through official social channels or via other unofficial ones which the users create.”

Figure 3 here. 
Figure 3 shows that, according to experts’ statements during the first round, customer influence can primarily affect the ways social networks support firms, as well as the design and promotion of products and services. However influencing prices seems more difficult. Nine out of 10 second-round interviewees later confirm this finding. For example, interviewees stress the importance of "the subsequent customer feedback component, which allows the industry to adapt the product or help the design of later products.” Networks are equally useful for products or services design because, in experts' words, “they represent an extremely important source of information about the tastes of the target public, and permit us to adapt the offer to the demand.”

Experts also state that customer almost never affect, since "other variables, which the users cannot manage, affect the price". Another expert states that "the topic of prices depends on many factors, even more so in cultural industries.” In short, "the user cannot determine the price policy, except for those cases where a great difference exists between the real price and what the user is willing to pay.”

\subsection{Profitability of social networks}

Results from the first round reveal that social networks use benefits cultural industries because these industries can improve revenues or reduce costs. Experts give a score of 6.3 (out of a maximum of 7) to this issue in the first round. Most (nine out of 10) confirm this statement in the second round with arguments such as, "Many of the cultural assets can be converted into a digital format and use networks as a direct sale channel.”; "It is profitable, but only in the long run with correct community management and through the achievement of the users' trust and complicity.”; and "social networks eliminate intermediaries and barriers. As a consequence these technologies reduce costs and facilitate the arrival of new customers and consumers.” 
Figure 4 here.

Figure 4 shows experts' statements in the first round that social networks are likely to improve profitability (greater revenues or fewer costs), especially in customers service and products promotion. Conversely, products or services design is the area where profitability less improves.

Once again, experts in the first round agree with this statement, which nine out of 10 interviewees support. Respondents claim that "customers express their preferences and receive better customer service from direct dialogue with firms. Promotion becomes easier when the firm speaks directly to the customer and does not involve the cost of the traditional mass media.”

All activities in Figure 4 receive a high score from experts. Profitability improvement receives a score of 5.5 out of 7, even in design. According to another expert, "we find ourselves at the beginning of a revolution which is going to change all industries completely. If used professionally, social networks can also improve profitability in product design to a great extent.”

\subsection{Ranking of social networks in cultural industries}

During the first round, interviewees responded to three different questions to assess several social networks and their importance within cultural industries.

Responses to these three questions shed light on the last aspect in Table 2. Experts state, during the first round, that top 5 social networks in cultural industries are Facebook, Twitter, Blogs, YouTube and LinkedIn, in that order (Figure 5). Although six out of 10 experts in the second round agree with this statement, this preference order is highly controversial, implying the difficulty of a ranking of these networks.

Figure 5 here. 
Some experts claim that they "agree because these networks are the ones with the highest traffic.” However, other comments do not confirm this conclusion, despite being equally interesting and deserving consideration. One of the experts states that "the ranking is missing Tuenti, the Spanish social network that the teenagers use more," and another indicates that "we forget useful platforms like geo-location ones.” All these comments do nothing but prove that, "it is very difficult to make a ranking." "It all depends on the cultural industry in question; every firm do not need to be present in every platform.”

\section{Discussion and conclusions}

Data on social network use illustrate that new technologies are first-rate business tools (Kiron, Palmer, Phillips, \& Berkman, 2013). Firms—especially those of cultural sector-must promote their profiles in these networks, so that customers can distinguish them from other profiles.

The findings suggest that social networks use in industries essentially seeks to promote services, products and brands, and to collect information about consumers that can improve what firms offer to customers. These uses are utilitarian rather than expressive, despite the importance of emotions in the creation and consumption of

cultural assets. Cultural firms should pay more attention to internal and external network communities, rather than using these tools merely for information exchange purposes.

Motivations for using networks are essentially proactive and their low or nonexistent cost may possible lead to their deployment. This finding rises the conclusion using a poor profile and a weak strategy in social networks is as negative as being completely absent from these platforms. Participation in social networks definitely 
involves desingning a clear strategy with specific objectives and to maintain profiles, which is impossible to achieve at zero cost (Martins \& Patricio, 2013).

Customers’ influence undoubtedly increases when service or goods providers compete within social networks. The more brands and products in Web 2.0 and 3.0, the better for customers to compare prices and services and request customized online attention. Many customers take a further step and become prescribers, true digital evangelists, and prosumers. This finding supports previous studies highlighting customer’s role in creating value for firms (Rihova, Buhalis, Moital, \& Gouthro, 2013).

Although experts' ranking of the most commonly used social networks largely coincides with other international rankings (Nielsen, 2011), this correspondence is insufficient to present this list as a definitive ranking. Despite the unquestionable importance of Facebook, Twitter, Blogs, YouTube, and LinkedIn within cultural industries, other technologies are highly interesting too (e.g., Tuenti, a highly popular network among young population in Spain). In fact, new network that can invalidate any existing ranking are continually emerging.

This study has certain limitations. Although this descriptive study uses quantitative information, data treatment is essentially qualitative, so that results are not extensible to other researches. However, this method has the advantage of providing a means of ratifying, in the second round, first round results. This study affords opportunities for scholars to understand results from the experts' point of view. 


\section{References}

Bendle L, \& Patterson I. (2010). The centrality of service organizations and their leisure networks. The Service Industries Journal, 30(10), 1607-1619.

Bodendorf F, \& Kaiser C. (2009). Detecting opinion leaders and trends in online social networks. Proceedings of the 2nd ACM workshop on Social Web Search and Mining, 65-68.

Buckley Ch. (1995). Delphi: a methodology for preferences more than predictions. Library Management, 16(7), 16-19.

Bughin J, \& Chui Ch. (2010). The rise of the networked enterprise: Web 2.0 finds its payday. McKinsey Quarterly, December, 1-9.

Casaló LV, Flavián C, \& Guinalíu M. (2010). Antecedents and consequences of consumer participation in on-line communities: The case of the travel sector. International Journal of Electronic Commerce, 15(2), 137-167.

Chai S, \& Kim M. (2012). A socio-technical approach to knowledge contribution behaviour: an empirical investigation of social networking sites users. International Journal of Information Management, 32(2), 118-126.

Dhaliwal JS, \& Tung LL. (2000). Using group support systems for developing a knowledge-based explanation facility. International Journal of Information Management, 20(2), 131-149.

Garrigós-Simón FJ, Lapiedra-Alcamí R, \& Barberá-Ribera T. (2012). Social networks and Web 3.0: their impact on the management and marketing of organizations. Management Decision, 50(10), 1880-1890.

Gneiser M, Heidemann J, Klier M, Landherr A, \& Probst F. (2012). Valuation of online social networks taking into account users’ interconnectedness. Information Systems and E-Business Management, 10(1), 61-84. 
González R, Gascó L, \& Llopis J. (2006). Information systems manager’s view about outsourcing in Spain. Information Management \& Computer Security, 14(4), 312- 326.

González R, Gascó J, \& Llopis J. (2010). Information systems outsourcing, a delphi study from Spain. Business Process Management Journal, 16(2), 224-263.

Greenacre L, Freeman L, \& Donald M. (2013). Contrasting social network and tribal theories: An applied perspective. Journal of Business Research, 66(7), 948-954.

Haegeman K, Cagnin C, Könnölä T, \& Collins D. (2012). Web 2.0 foresight for innovation policy: A case of strategic agenda setting in European innovation. Innovation: Management, Policy \& Practice, 14(3), 446-466.

Hayne SC, \& Pollard CE. (2000). A comparative analysis of critical issues facing Canadian information systems personnel: a national and global perspective. Information \& Management, 38(2), 73-86.

Joo Y-H, Kim Y, \& Yang S-J. (2011). Valuing customers for social network services. Journal of Business Research, 64(11), 1239-1244.

Kaynak E, Bloom J, \& Leibold M. (1994). Using the Delphi technique to predict future tourism potential. Marketing Intelligence \& Planning, 12(7), 18-29.

Kiron D, Palmer D, Phillips N, \& Berkman R. (2013). The executive’s role in social business. MIT Sloan Management Review, 54(4), 83-89.

Koch H, Gonzalez E, \& Leidner D. (2012). Bridging the work/social divide: The emotional response to organizational social networking sites. European Journal of Information Systems, 21(6), 699-717.

Loo R. (2002). The Delphi method: a powerful tool for strategic management. Policing: an International Journal of Police Strategies \& Management, 25(4), 762-769. 
Magnier-Watanabe R, Yoshida M, \& Watanabe T. (2010). Social network productivity in the use of SNS. Journal of Knowledge Management, 14(6), 910-927.

Martins CS, \& Patricio L. (2013). Understanding participation in company social networks. Journal of Service Management, 24(5), 567-587.

Nielsen. (2012, April). State of the media: The social media report, retrieved October 10, 2012, from http://cn.nielsen.com/documents/Nielsen-Social-MediaReport_FINAL_090911.pdf.

Okazaki S, Rubio N, \& Campo S. (2013). Gossip proneness on promotional e-wom through social networking sites. Universia Business Review, (39), 32-49.

Okoli C, \& Pawlowski SD. (2004). The Delphi method as a research tool: an example, design considerations and applications. Information \& Management, 42(1), 1529.

Rihova I, Buhalis D, Moital M, \& Gouthro M. (2013). Social layers of customer to customer value co-creation. Journal of Service Management, 24(5), 553-566.

San José-Cabezudo R, Camarero-Izquierdo C, \& Rodríguez-Pinto J. (2013). The persuasion context and results in online opinion seeking: Effects of message and source - The moderating role of network managers. Cyberpsychology, Behavior, and Social Networking, 16(11), 828-835.

Sánchez-Franco MJ, Buitrago-Esquinas EM, \& Yñiguez R. (2012). How to intensify the individual's feelings of belonging to a social networking site?: Contributions from community drivers and post-adoption behaviours. Management Decision, 50(6), 1137-1154.

Sashi CM. (2012). Customer engagement, buyer-seller relationships and social media. Management Decision, 50(2), 253-272. 
Sinclaire JK, \& Vogus CE. (2011). Adoption of social networking sites: And exploratory adaptive structuration perspective for global organizations. Information Technology Management, 12(4), 293-314.

Sledgianowski D, \& Kulviwat S. (2009). Using social network sites: The effects of playfulness, critical mass and trust in a hedonic context. The Journal of Computer Information Systems, 49(4), 74-83.

Xu Ch, Ryan S, Prybutok V, \& Wen Ch. (2012). It is not for fun. An examination of social network site usage. Information \& Management, 49(5), 210-217.

Zaglia ME. (2013). Brand communities embedded in social networks. Journal of Business Research, 66(2), 216-223.

Zhong X, Huang Q, Davidson RM, Yang X, \& Chen H. (2012). Empowering teams through social network ties. International Journal of Information Management, 32(3), 209-220. 


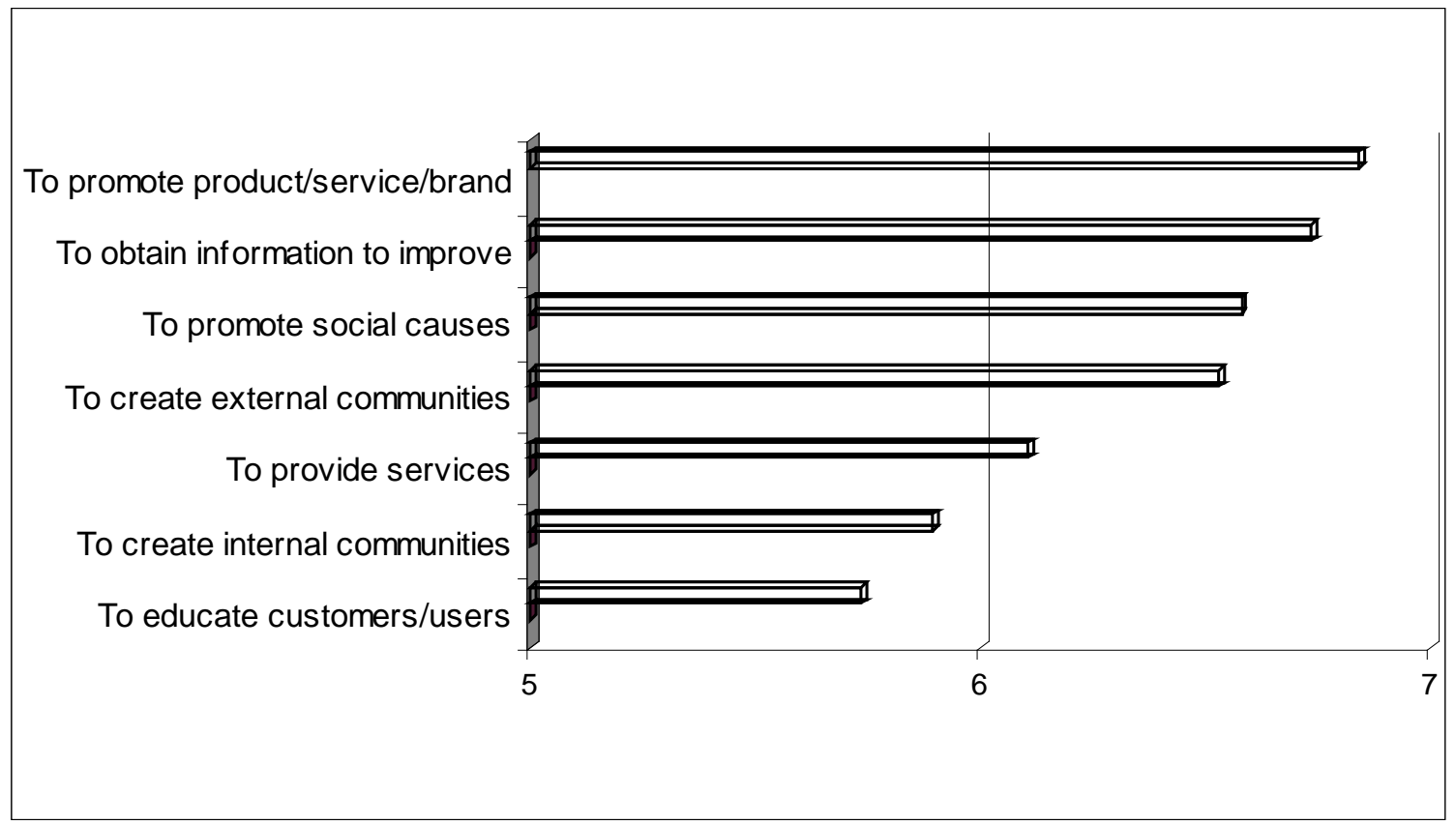

Figure 1: Social network use in cultural industries 


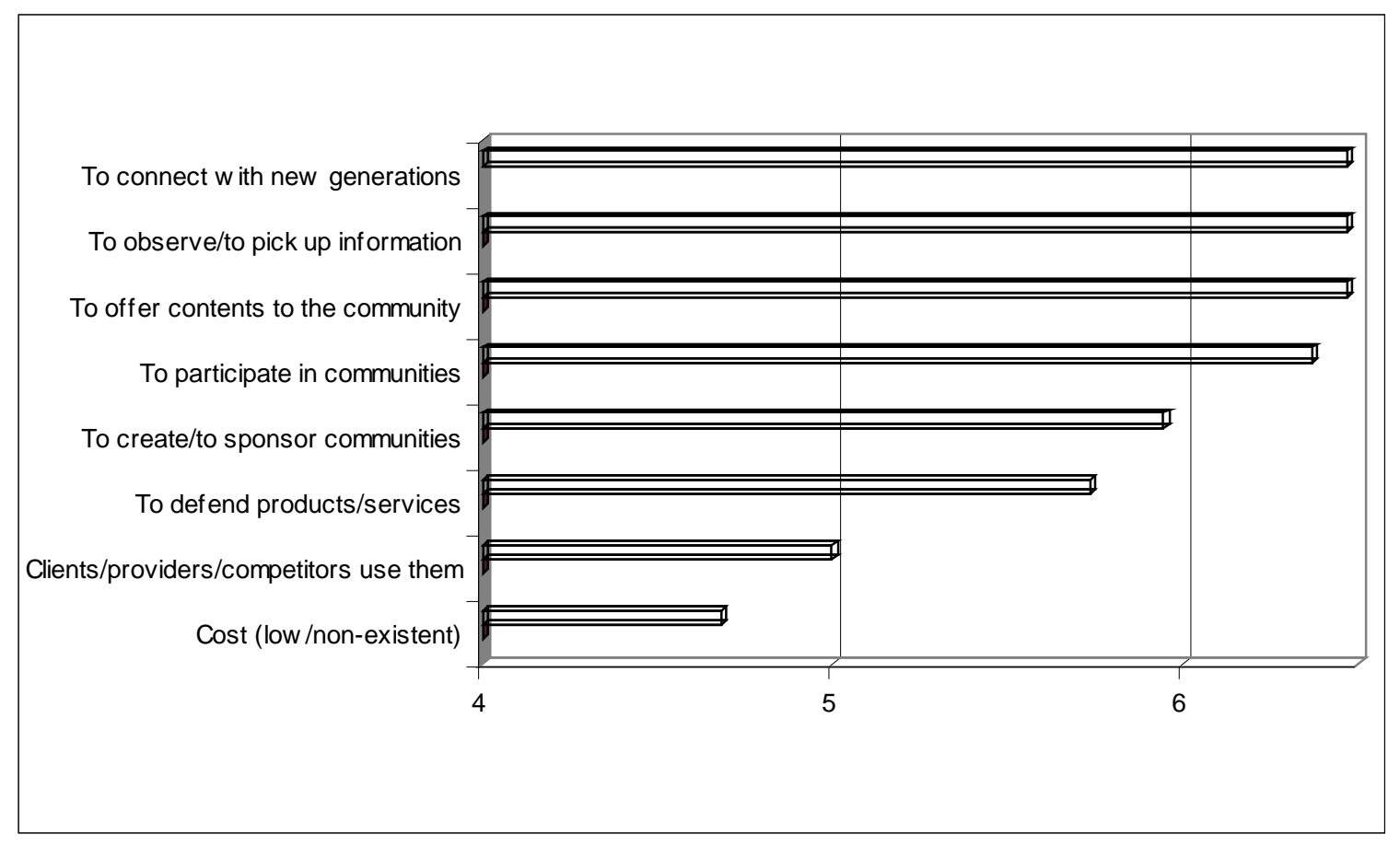

Figure 2: Motivations to use social networks in cultural industries 


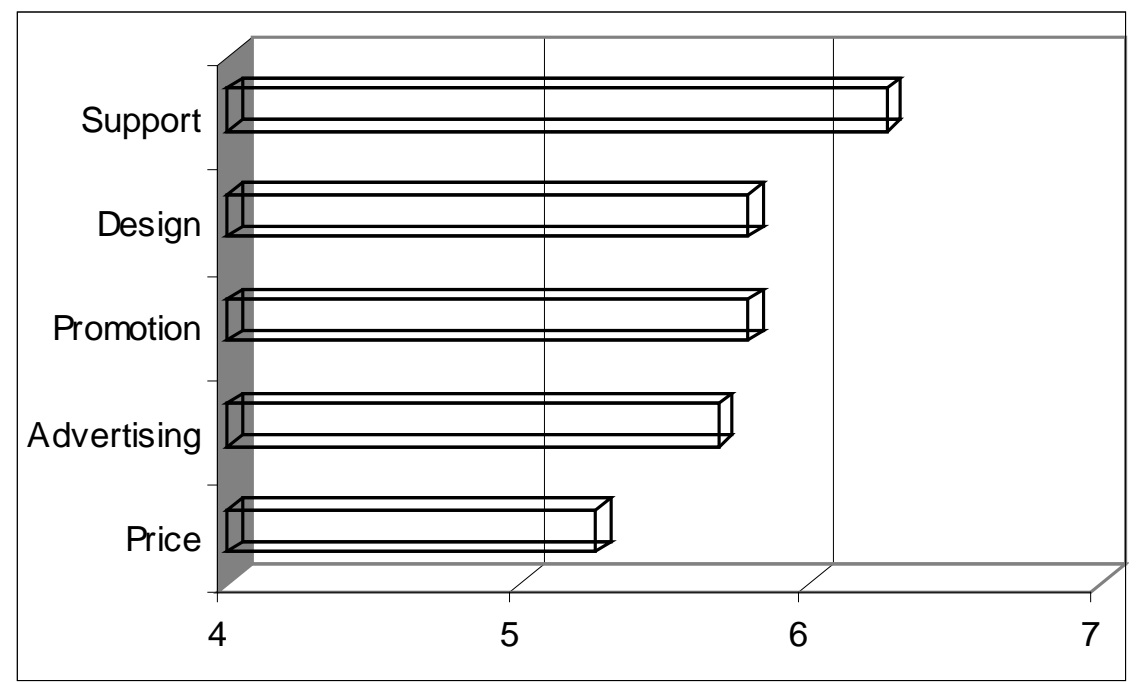

Figure 3: Influence of customers on cultural industries through social networks 


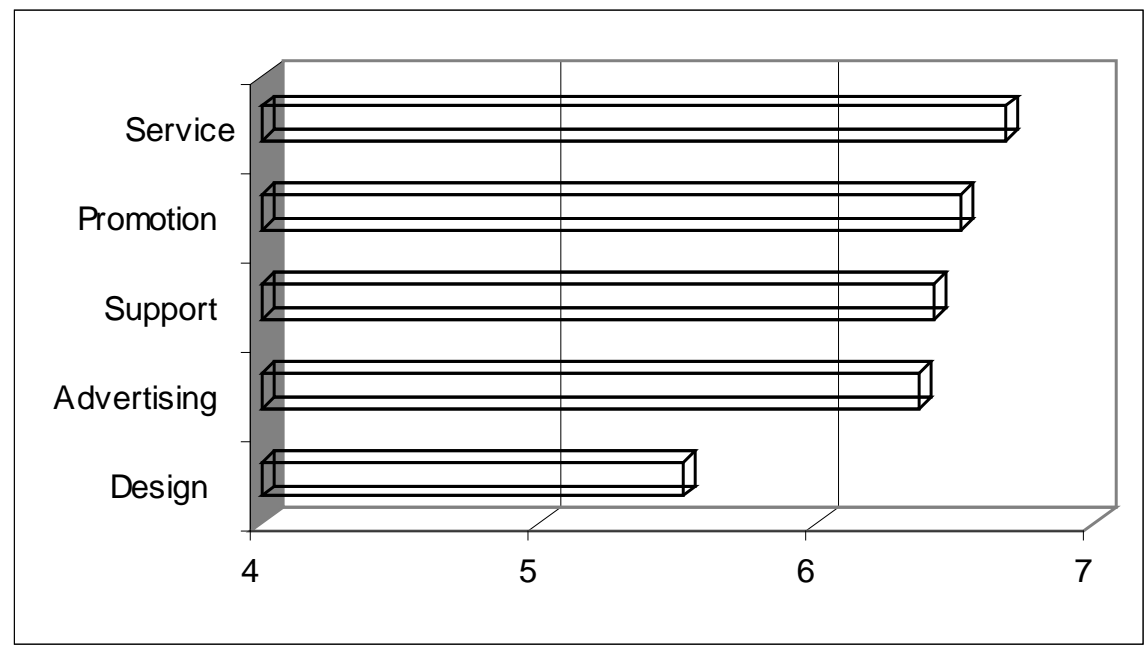

Figure 4: Revenue/cost improvement through social network use in cultural industries 


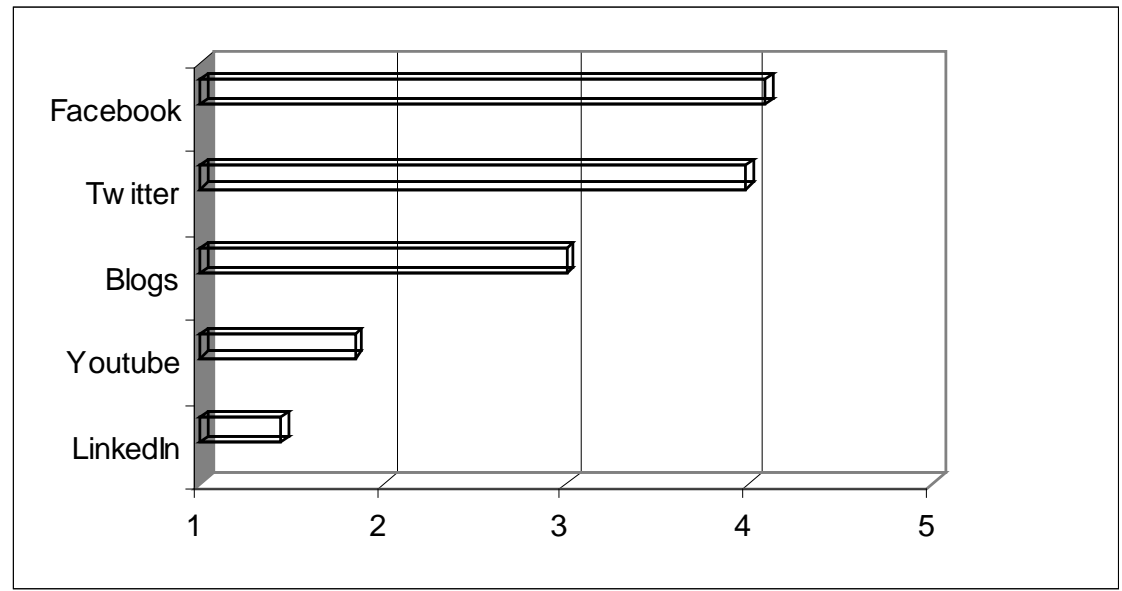

Figure 5: Utility of different network technologies in cultural industries 